\title{
Sexual Cannibalism as a Manifestation of Sexual Conflict
}

\author{
Jutta M. Schneider \\ Zoological Institute \& Museum, Biocentre Grindel, University of Hamburg, Hamburg, Germany \\ Correspondence: Jutta.schneider@uni-hamburg.de
}

Sexual cannibalism is a well-known example for sexual conflict and has many facets that determine the costs and benefits for the cannibal and the victim. Here, I focus on species in which sexual cannibalism is a general component of a mating system in which males invest maximally in mating with a single (monogyny) or two (bigyny) females. Sexual cannibalism can be a male strategy to maximize paternity and a female strategy to prevent paternity monopolization by any or a particular male. Considerable variation exists between species (1) in the potential of males to monopolize females, and (2) in the success of females in preventing monopolization by males. This opens up exciting future possibilities to investigate sexually antagonistic coevolution in a largely unstudied mating system.

Sexual cannibalism, the killing and consump$S$ tion of potential or actual mating partners in a mating context, has been termed a "pinnacle of sexual conflict" because of the dramatic ending of the act for one mating partner, mostly the male (Elgar and Schneider 2004). This contradiction of traditional sex roles may be one reason why the phenomenon of sexual cannibalism has intrigued naturalists for a long time. In the context of sexual conflict, sexually cannibalistic behavior of females is a harmful trait, and antagonistic traits are expected to evolve in males, which can be considered the reverse of most other examples in which females respond to male harm (see Perry and Rowe 2014). I will discuss potential antagonistic traits to sexual cannibalism in males but will also show that the above view is too simplistic when it comes to spider mating systems characterized by very low male mating rates.
It is important to note that there are different kinds of sexual cannibalism based on very different evolutionary scenarios (Elgar and Schneider 2004; Prenter et al. 2006; Wilder et al. 2009). The most extreme divide exists between cannibalism before sperm transfer, which can only benefit the cannibal, and sexual cannibalism during or after sperm transfer (from here on termed postinsemination sexual cannibalism), which can benefit the cannibal and the victim (Elgar and Schneider 2004). Despite a longer history of research on preinsemination sexual cannibalism, the evolutionary causes and consequences of postinsemination sexual cannibalism are generally less debated.

There are reports (often anecdotal) on the occurrence of sexual cannibalism from diverse invertebrate taxa (Elgar 1992) and it may well occur in all predatory invertebrates that are potentially cannibalistic (Polis 1981). It is beyond

Editors: William R. Rice and Sergey Gavrilets

Additional Perspectives on The Genetics and Biology of Sexual Conflict available at www.cshperspectives.org

Copyright (C) 2014 Cold Spring Harbor Laboratory Press; all rights reserved; doi: 10.1101/cshperspect.a017731

Cite this article as Cold Spring Harb Perspect Biol 2014;6:a017731 
J.M. Schneider

the scope of this brief review to list and evaluate all reported occurrences. Rather, I will start with a brief account of the generally discussed causes and consequences of sexual cannibalism and will then concentrate on the conflicting interests of the sexes regarding postinsemination sexual cannibalism in mating systems that are characterized by very low male mating rates.

Studies that investigate sexual cannibalism experimentally are mostly concerned with (1) nutritional aspects, (2) the importance of sexual size dimorphism and sexual selection, and, increasingly, (3) behavioral syndromes. The aggressive spillover hypothesis suggests that preinsemination sexual cannibalism is part of a behavioral syndrome in which aggression against mating partners spills over from a foraging context (Arnqvist and Henriksson 1997). There is mixed support for this idea in the few species that have been looked at. In several spider species, females consistently differ in their aggressiveness and these differences affect sexual cannibalism (for a recent debate about the evidence for this hypothesis, see Johnson 2013; Kralj-Fišer et al. 2013b; Pruitt and Keiser 2013).

A majority of studies have taken a unilateral view and have been concerned with the "motivation" of the cannibal; because sexual cannibalism generally occurs in predators, hunger is a well-supported motivation (Wilder et al. 2009). Many predators are food-limited, and, assuming a trade-off between foraging and mating, the balance may tilt toward foraging under particular circumstances (modeled by Newman and Elgar 1991). Food and mate availability will influence the costs and benefits of sexual cannibalism for females and have been one focus of a recent review on sexual cannibalism (Wilder et al. 2009).

In all predatory and cannibalistic animals, mating partners impose selection on each other's abilities to avoid or resist aggression. This selection pressure is asymmetrical if one sex is physically dominant. Indeed, the differences in size between females and males often determine the frequency of sexual cannibalism, perhaps because the potential to resist a cannibalistic attack is size-dependent (Elgar 1992; Wilder and Rypstra 2008). Usually, males are the vic- tims and females are the cannibals. Yet, reversed sexual cannibalism has also been reported and appears to be associated with the reversed pattern in sexual size dimorphism. Examples are the water spider, Arygoneta aquatica (Schutz and Taborsky 2005, 2011) and role-reversed wolf spiders (Aisenberg et al. 2011). In the gnaphosid spider, Micaria sociabilis, large, young males cannibalize old and relatively smaller females (Sentenska and Pekar 2013). These examples further support the notion that the relative size differences of a mating pair play a part in determining the likelihood of sexual cannibalism. Patterns can be found both on a betweenspecies comparative scale and on a within-species scale (Wilder and Rypstra 2008; Wilder et al. 2009), and they are also reported as an underlying pattern in cannibalism outside a mating context (Bleakley et al. 2013). Furthermore, there is anecdotal evidence for the same pattern in hermaphrodites (e.g., Goto and Yoshida 1985; Michiels et al. 2003), which may constitute a particularly interesting case to study, as the power asymmetries are less obviously related to the male or female role.

In asymmetric encounters, the costs and risks of aggressive behavior toward potential mating partners are low for the dominant partner. Toward smaller males, females could use aggressiveness as a means of partner choice. Indeed, many studies suggest that sexual selection in addition to gaining a meal may be the adaptive value of sexual cannibalism (Prenter et al. 2006). From the female perspective, aggressive behavior directed toward males may serve as a general screening of partner quality, a mechanism often described as indirect mate choice (Elgar and Nash 1988; Prenter et al. 2006; Kralj-Fišer et al. 2012). A screening method implies that females attack every male, and suitors that cannot withstand and persist an attack will be killed and consumed; alternatively, females may differentiate between males and attack and consume only those males that do not meet certain quality criteria (reviewed in Prenter et al. 2006). The latter has been found in wolf spiders (Wilgers and Hebets 2012). The latter mechanism of direct choice is more complex than the indirect one as it requires percep- 
tion and assessment of quality cues, and large enough benefits of choosiness are expected to match the costs. Mate rejection via sexual cannibalism is considered a particularly extreme case of sexual conflict mostly because rejection can lead to death. Although this may be true for the individual male that loses all future reproductive success, frequencies of preinsemination sexual cannibalism might be rather low (KraljFišer et al. 2013b). Please note that in almost every species, a certain proportion of individuals will be excluded from the mating market and will have no mating success. The claim that prevention of mating success via sexual cannibalism results in more intense sexual conflict than exclusion from mating with less drastic measures has, to my knowledge, never been tested. Because of the scarcity of data on natural frequencies of preinsemination cannibalism, a meta-analysis would not reveal a realistic picture at this stage. Hence, to date, it is not feasible to compare the relative strength of selection imposed by a cannibalistic mate choice strategy against a strategy with less drastic consequences of mate rejection. More studies are needed to unravel the exact nature of sexual selection under the threat of ending as a meal. Below, I will briefly sketch possible responses to selection imposed by sexually cannibalistic females before or during insemination.

\section{RESPONSES TO THE THREAT OF SEXUAL CANNIBALISM}

Sexually cannibalistic animals are generally invertebrate predators equipped with sensory and motor skills that facilitate hunting success. For a male who has to approach a potential mate that is a voracious and often larger predator, attention and communication are vital (Schneider and Andrade 2011; Uhl and Elias 2011). The mate approach of, for instance, many spiders and mantises is indeed described as very cautious. In some species, sexual cannibalism may nevertheless occur before copulation because a courting male is unable to reveal his identity to the female, who will then mistake the male for prey (Gould 1984). Such signaling errors may occur when the channels of communica- tion are disturbed. Vibratory signaling could be impaired because of missing legs and chemical signaling owing to poor condition or old age as suggested by Sentenska and Pekar (2013). Cases of sexual cannibalism resulting from mistaken identity emphasize the importance of signaling and incidences are expected to be rare and accidental. Evidently, this nonadaptive explanation does not address the evolution of the phenomenon of sexual cannibalism.

Sexual cannibalism will select for male abilities to assess the potential risks and benefits of a mating attempt. Indeed, perception of cues that elucidate receptivity and perhaps quality of females are reported for several species of spiders (Foelix 2011 and references therein) and mantids (for praying mantis, see Lelito and Brown 2006; Barry et al. 2010; Watanabe and Yano 2012).

Recent studies have shown that the risk of sexual cannibalism before insemination can vary owing to consistent individual differences in aggressiveness of females within species (Pruitt and Riechert 2012), and therefore male sensory ability to detect this variation in danger is expected to evolve (Berning et al. 2012; Johnson 2013; Kralj-Fišer et al. 2013a,b; Pruitt and Keiser 2013). In the bridge spider, Larinioides sclopetarius, individuals of both sexes consistently differ in their aggressiveness (Kralj-Fišer and Schneider 2012). The mating pattern is positively assortative in that nonaggressive males preferentially mate with nonaggressive females (Kralj-Fišer et al. 2013a). It remains to be investigated whether males are able to assess female personality and adjust their behavior accordingly. Hunger will also influence the inclination of a female to attack a male (MoyaLarano et al. 2003; see also Rabaneda-Bueno et al. 2008), and, for example, a male black widow can judge from web cues alone whether a female is starved or well fed, the latter of which they prefer (Johnson et al. 2011). Males can also determine whether females are virgin or mated, and already mated females may impose a relatively larger risk of sexual cannibalism (Johnson 2001; Rabaneda-Bueno et al. 2008). However, there are many other possible explanations of males rejecting mated and hungry females. Rig- 
J.M. Schneider

orous experimental approaches are essential to verify that avoidance of sexual cannibalism is behind male behavior, but to experimentally manipulate the risk of sexual cannibalism is challenging (Herberstein et al. 2011).

The differences in risks imposed by different females may be strong enough to favor the evolution of male mate choice. In praying mantis, Barry et al. (2010) found that males prefer larger and more fecund females in a binary choice situation, but poor-condition females are not rejected in a sequential encounter scenario. Barry and Kokko (2010) showed in a model that even under the threat of sexual cannibalism, male mate choice may not evolve if mating opportunities are sufficiently limited. However, even under such conditions, a compromise between the need to secure a mating and mate choice may evolve as has been found in some spiders. This strategy would be analogous to the trading-up strategy used to explain multiple mating in females (Jennions and Petrie 2000). For instance, males of the highly sexually cannibalistic Argiope bruennichi can mate maximally twice and they readily mate with low quality females and with siblings suggesting the absence of choosiness. However, they copulate only very briefly with less preferred females and thereby double their chances of surviving their first copulation. Singly mated males can then walk off to search for another female that ideally will be of higher quality (bigynous mating strategy) (Welke and Schneider 2010; Fromhage and Schneider 2012; Welke et al. 2012). In general, mate choice should evolve if mating costs are very high for males, because quality differences between females, if present, matter a lot for the lifetime reproductive success of a male that has a maximum mating rate of two (modeled by Fromhage and Schneider 2012). However, even in systems with low male mating rates and a theoretical expectation of male mate choice, cognitive demands and constraints may have to be taken into account as well. For example, it may be questionable whether a spider brain easily evolves the capacity to evaluate and compare qualities of several potential mating partners and to make a decision based on information that requires memory and comparisons of quality traits. Nevertheless, cognitive costs of male choice may be modest if, for example, a threshold rule is used as a base for the decision to mate or not (Real 1990).

The threat of sexual cannibalism has likely shaped courtship rituals (Robinson and Robinson 1980; Robinson 1982) and is considered responsible for a multitude of mating strategies and adaptations. Males of some orb-web spiders court on a special mating thread, which either connects the hub of the web to a support structure or is produced within the web after removing part of the capture web (Elgar 1991). Generally, the female will leave her position in the hub of the web or in a retreat and move onto this thread for copulation. The male then has the option to drop quickly without landing in the capture web, should the female attack. Courtship on such a thread is therefore considered safer for males. Elgar (1991) suggested that these differences in the mating position and the associated differences in risks for males select for morphological differences; as, for example, leg length, if males with longer legs are better able to escape sexual cannibalism. Risk-sensitive behavioral strategies are also expected. For example, in cannibalistic Mediterranean tarantulas, males approach and court females outside the hunting periods (Moya-Larano et al. 2004). In many species, males adopt opportunistic strategies and copulate while the female is occupied with feeding or while she is molting to maturity (Robinson and Robinson 1980; Fromhage and Schneider 2005c). A few spiders such as Pisaura mirabilis induce such an event by presenting a nuptial gift in the form of a prey item (Prokop and Maxwell 2009). Males wrap the gift in silk, which helps the male to remain in contact with the gift if the female interrupts copulation (Andersen et al. 2008). The dense wrapping can also disguise a worthless gift as for example a dried insect carcass without nutritional value (Albo et al. 2012). Furthermore, courting males have been found to induce catalepsy in females (Singer et al. 2000; Becker et al. 2005) or pacify females through tactile courtship (Stoltz et al. 2008).

There is a large body of suggestive evidence of adaptations in males that function to reduce 
the risk of sexual cannibalism, but there are very few rigorous experimental studies. Experimental approaches have been adopted in two studies of golden orb-web spiders. In Nephila pilipes, males are very small in comparison to females and sometimes get killed and eaten during copulation. During courtship, the tiny male surrounds the female body by repeatedly laying down silk, although the silk cannot truly restrain the female (Robinson and Robinson 1973). This behavior is called "mate binding" and was interpreted as a counter adaptation to the threat of sexual cannibalism (Kuntner et al. 2009b). Suggestive evidence for this comes from staged matings showing that mate binding mostly occurs after the female has aggressively terminated the first copulation. In an elegant experiment, Zhang et al. (2011) silenced chemoreception and/or disabled tactile perception of females, and males were manipulated to be able or unable to lay down silk during courting. Males were less able to calm females if they could not produce silk and if female tactile perception was disabled. The results of this study show that the male behavior reduced the likelihood of females reacting aggressively toward a second mating attempt of the same male. In the congener, Nephila fenestrata, males have the option to copulate after the female has captured a prey item. However, after some time, they also mate with females that are not feeding (Fromhage and Schneider 2005c). Experimental staging of copulations with and without prey showed that all males survived copulation when the female was feeding, whereas $33 \%$ of the males were captured and consumed in the treatment without prey (Fromhage and Schneider 2005c). Sexual cannibalism after copulation is costly for males in this species because surviving males can successfully prevent loss of paternity by mate guarding (Fromhage and Schneider 2005c).

In summary, evidence is accumulating that sexual cannibalism is a selective agent responsible for a high diversity of behavioral, sensory, and morphological counter adaptations in males. For the rest of this review, I will focus on species where postinsemination sexual cannibalism is a regular occurrence and co-occurs with a particular mating system (see below). In these cases, postinsemination sexual cannibalism may be a male strategy to increase paternity share or a female response to male adaptations in the context of sperm competition. Both options evolved under sexual selection and sexual conflict. In the examples below, it is indeed the killing and much less the feeding that is the motivation behind the aggression. In other words, females will attack to kill, but once a kill is made, the female may just as well consume the body. By restricting myself to such cases, I largely ignore the rich literature on nutritional aspects of feeding on conspecifics, which is a highly interesting field in itself.

\section{MALE MATING STRATEGIES IN MONOGYNOUS OR BIGYNOUS MATINGS SYSTEMS}

Superficially, the notion that sexual cannibalism can be part of a male mating strategy seems to be at odds with the claim that sexual cannibalism involves a strong sexual conflict. To fully comprehend the phenomenon, we need to dissect the mating system and measure the costs and benefits of killing and being killed for both sexes.

Monogynous mating systems are rare but occur in diverse taxa such as fish, crustaceans, insects, and spiders. Within the entelegyne spider subgroup, there are at least four independent origins of such a mating system in which males are adapted to mate with a single or maximally two females (monogyny, bigyny), whereas the females are polyandrous (Miller 2007; Schneider and Fromhage 2010; Schwartz et al. 2013). A theoretical model suggests that monogyny can evolve when more males than females mate (male biased effective sex ratio) (Fromhage et al. 2005). Such a bias can occur if the tertiary sex ratio is male biased, for example, because more males than females survive to maturation. Assuming a male bias and polyandry, the average expected paternity success of polygamous males will be smaller than one (Fromhage et al. 2005). It then pays to invest maximally into mating with one female only (monogynous male mating strategy), if this will elevate paternity success above the average. 
To achieve above average paternity, monogynous males must possess means to protect their sperm against rivals by outcompeting rival ejaculates or preventing female remating (Fromhage et al. 2008).

Allowing or even inviting sexual cannibalism is one way for a male to achieve this goal. For instance, in two Latrodectus species, males perform a characteristic somersault during copulation, which will bring their abdomen right on top of the female chelicerae and which may facilitate cannibalism by the female (Forster 1992; Segoli et al. 2008). Thereby, males prolong their copulation duration and reduce the female propensity to remate (Andrade 1996). However, females have two spermathecae that cannot both be inseminated during a single copulation. Males have paired mating organs too, the pedipalps, which are secondary mating organs of spiders that are charged with sperm, and males can only use one pedipalp at the time (see Fig. 1 for an illustration of male and female sexual organs in selected spider species). Hence, although the male benefits from prolonging his first copulation, he also increases the risk of dying before he was able to use his second pedipalp. Males should make sure they survive for as long as necessary to empty both their pedipalps. Male Latrodectus hasselti can do so by pulling their inner organs to the front of the abdomen, for instance, away from the area where the female will insert her mouth parts, before they attempt the first copulation (Andrade et al. 2005). Even though the female may start feeding on the copulating male, he has a good chance of surviving the first somersault and mating. Survival enables males to return to the same female where they finally sacrifice their life during the second insertion and the second somersault (Andrade et al. 2005).

In species of Tidarren and Echinotheridion, two genera within the same family as Latrodectus (Theridiidae), males mature shortly after hatching at a very small body size. The paired pedipalps are very large compared to the body, and during development, males actively detach one pedipalp (Knoflach and van Harten 2001). On finding a female, the one-palped males will inseminate one of the two spermathecae of a single female and invariably die during their only copulation. The dead body will temporally prevent rivals from using the same genital opening. However, the males cannot protect the still virgin side of the female and hence accept the risk that a second male may inseminate the other spermatheca. Inferring from the above model (Fromhage et al. 2005), such a strategy can be evolutionary stable if the expected reproductive success of a male that fertilizes $50 \%$ of the eggs of a female is still higher than the expected reproductive success of an alternative strategy. If the male effective sex ratio bias is larger than two, this condition would be met because the average paternity success of a polygamous male would be $<50 \%$. Alternatively, the mating strategy will pay off if many females will not mate multiply. The mating system of these onepalped spiders can be safely considered monogynous, although natural mating rates of females are unknown for all these species (Knoflach and van Harten 2001). In the above examples, sexual cannibalism is a regular element of the mating procedure that is actively solicited by the males, either because they position themselves onto the fangs of the females or because they die during mating. Hence, the act of dying during copulation is not against the male interest, although it may oppose female interests. However, males may not be indifferent to the timing of their death if they have additional mating options, regardless of whether these options are with the same or a different female.

A monogynous male mating strategy is only better than a polygynous alternative if the male can efficiently protect his paternity. Male death alone, however, cannot always prevent females from remating or rivals from threatening paternity. Interestingly, very similar mechanisms of postcopulatory and even postmortal paternity protection have evolved independently in those same spider families that are characterized by monogynous species (Foellmer and Fairbairn 2003; Miller 2007; Schwartz et al. 2013). Males of most Argiope species, several theridiids such as Latrodectus and Tidarren, and some Nephilidae break off parts of their genitalia during copulation, which remain inside the female and hinder further inseminations (Uhl et al. 2010). 


\section{A}
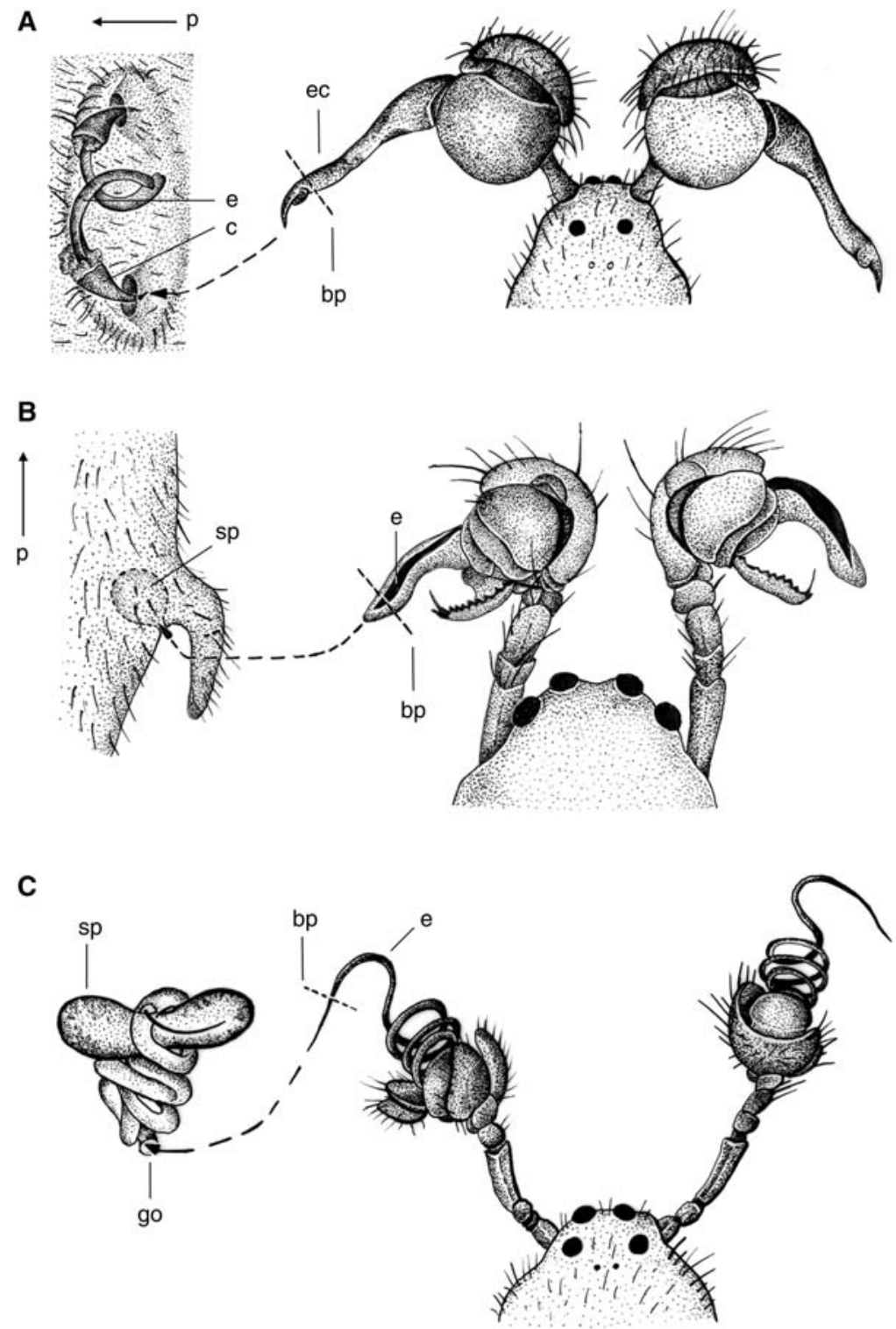

Figure 1. Drawings of male (right) and female (left) spider genitalia from one representative of three spider families in which mating plugs through genital damage evolved independently. Males possess two pedipalps, which are secondary genitalia that get charged with sperm after maturation; female genitalia possess two copulatory openings each leading to an independent spermatheca. During copulation, males transfer sperm into one spermatheca at a time with one pedipalp. The tip of the intromittent organ breaks and obstructs the copulatory opening $(A, B)$ or the entrance of the spermatheca $(C)$. (Top) In Nephila fenestrata (Nephilidae), the tip of the male sperm transfer organ (embolic conductor, ec) breaks and remains stuck in the genital opening. Males often use both pedipalps with the same female and obstruct both of her genital openings as depicted. Plugs are visible. (Middle) A. bruennichi (Araneidae) have very complex pedipalps that unfold during copulation. Some sclerites attach to the protrusion above the female genital openings, the scape. The tip of the embolus (e) breaks and blocks one of two copulatory openings. The spermatheca sits right behind the entrance as depicted connected to the outside by a short duct. The plugs cannot be easily seen from the outside because of the scape. (Bottom) In Latrodectus hasselti (Theriididae), males have a coiled embolus (e) that has to be pushed all the way up the equally coiled insemination duct of the female. Here, only the internal insemination duct and one spermatheca are drawn. The tip of the embolus reaches into the lumen of the spermatheca and may break off there. Hence, in this species, the plug is deep inside. $\mathrm{p} \rightarrow$, point to the anterior end of the female; bp, breakage point; e, embolus; c, conductor; ec, embolic conductor; go, genital opening; sp, spermatheca. $A$ redrawn and modified from Fromhage and Schneider (2006), B from Uhl et al. (2007), and $C$ from Snow et al. (2006). Drawings are not to scale. 
J.M. Schneider

Males in some other species plug the opening from the outside; again, others obstruct the connection of the insemination duct to the spermatheca (see Fig. 1 for examples of both patterns). The latter may not prevent further copulations, but a rival will not be able to transfer sperm into the sperm storage organ and will gain no paternity as a result (Snow and Andrade 2004; Snow et al. 2006). Mating plugs also exist in other, less cannibalistic spiders but are then composed of secretions and not of genital fragments at high costs (Uhl et al. 2010).

For the male, the cost of a plugging mechanism based on his genital parts is sterility, as each pedipalp can be used once only caused by the damage. Sterility has no negative implications for reproductive success in a monogynous or bigynous mating system where each pedipalp is needed only once anyway to inseminate and then seal the two spermathecae of a single female. Intriguingly, not every male succeeds in breaking off the tip of the genital or in positioning the piece in the accurate location (e.g., Neumann and Schneider 2011). Another challenge to the goal of protecting ones sperm is that plugs can be removed or fall out. If the probability of overcoming these impediments is summarized as plug effectiveness, there are pronounced differences between species. If rivals can remove or bypass plugs, males can benefit from surviving copulations and defending the female as eunuchs. Males of N. fenestrata, for example, often survive copulations but nevertheless leave a plug behind (Fromhage and Schneider 2006). However, males of this species are capable of bypassing plugs of rivals (Fromhage and Schneider 2005c) and can achieve a considerable paternity share with a mated female, thereby reducing the paternity share of the previous male. Therefore, males with damaged genitalia benefit from guarding their female. These eunuchs, which have no reproductive future at stake, will readily escalate a fight and succeed in chasing away much larger opponents (Fromhage and Schneider 2005a; Kralj-Fišer et al. 2011). Males of Nephilengys malabarensis copulate by detaching the entire pedipalp, which will continue to transfer sperm into the female independently (Li et al. 2012). Males without pedipalps are better fighters than males with pedipalps (Lee et al.2012), possibly because the pedipalps are somehow in the way or constitute an extra weight. Hence, although sexual cannibalism often co-occurs with a monogynous mating system, it is not tightly linked.

The above examples show males that invest maximally in protecting their paternity by sacrificing genitalia and their lives, and, in some cases, this involves enforcing monogamy on females. Assuming that females benefit from polyandry, counteradaptations that prevent male monopolization are expected (see Edward et al. 2014). Investigating between species variation and evolutionary correlations of plug effectiveness versus sexual cannibalism may be very revealing.

\section{FEMALE COUNTERSTRATEGIES IN MONOGYNOUS OR BIGYNOUS MATINGS SYSTEMS}

Assuming traditional sex roles, females are expected to be selective in their choice of mating partner. In predatory and cannibalistic animals, mate rejection can lead to an extra benefit by ending in a meal (see above). This benefit may be large enough to favor adaptations that facilitate this ending. Natural selection will likely put a limit to such adaptations if they occur before a sufficient sperm load has been secured, as very aggressive females may risk remaining unmated.

Indeed, observations on several spider species suggest that female spiders initially accept any male at least for a first copulation (Wilder and Rypstra 2007). If another mating opportunity arises, females may only remate with a male of higher quality than the previous one (tradeup strategy) (Halliday 1983). Unselective mating of virgins followed by a trade-up strategy is particularly likely if selective females have an increased risk of remaining unmated (Kokko and Mappes 2005). Alternatively, females may mate multiply and mix paternity or they may cryptically favor the sire of highest quality. As Kokko and Mappes (2013) suggest in a recent model, multiple mating might be a better null model for explaining female mating rates than 
monandry especially if mating is not very costly, a condition that may well apply in sexually cannibalistic spiders. Under conditions in which the number of mates is unpredictable and where it can be very low, females will benefit more from securing a sperm supply than from choosiness. Interestingly, although entelegyne spiders that include all species mentioned here possess two spermathecae (Foelix 2011), the filling of a single one may be enough to ensure fertilization of all eggs (Schneider et al. 2005). It is tempting to speculate that a second spermatheca is a good option to secure the potential of multiple mating in species with a highly efficient plugging mechanism of males.

In polyandrous mating systems, it is widely accepted that transfer of spermatozoa is only one of many functions of copulation (Eberhard 1996) and that sperm competition selects for male strategies that influence sperm use (Kelly and Jennions 2011; Edward et al. 2014) or female remating (Uhl et al. 2009; Alonzo and Pizzari 2013; Kvarnemo and Simmons 2013). In addition to the common costs of copulation, males may cause harm to females (e.g., Chapman et al. 1995; Morrow et al. 2003; Ram and Wolfner 2007; Sirot et al. 2014). If these processes are a function of copulation duration, and male and female interests do not coincide, females will benefit from exerting control over the termination of copulation (Elgar et al. 2000). Sexual cannibalism during mating may be a very efficient and even nutritious means to control the duration of copulation and thereby regulate relative paternity of males. Such a function would imply that sexual cannibalism shortens the duration of copulation (Elgar 1995). However, within species displaying regular sexual cannibalism during copulation, sexual cannibalism has been found to prolong copulation (Andrade 1996; Schneider et al. 2006). Perhaps sexual cannibalism has initially evolved as a female strategy to end copulation, and males have coevolved effective means that nevertheless permit a prolonged attachment of their genitalia. The highpoint of this antagonistic coevolution may be the continuous sperm transfer by a detached pedipalp (remote copulation) (Knoflach and van Harten 2001; Li et al. 2012).
Aggressive behavior during mating may have enabled females to terminate genital contact and control ejaculate transfer. Among other things, this power asymmetry may have triggered a coevolution in male and female genitalia (Kuntner et al. 2009a). Female control depends on the genital coupling mechanism, and the strength of genital attachment will determine whether females can induce detachment rapidly enough to influence sperm transfer. Secure attachment will prevent females from ending copulation as evidenced by cases in which male parts, or whole males, remain stuck in the female genital opening after they have been attacked and even died (Knoflach and van Harten 2001; Schneider et al. 2001; Foellmer and Fairbairn 2003). Spider species vary widely in their genital morphology and genital coupling mechanisms (Eberhard 2004a), and firmness of the genital coupling may be a result of a sexual conflict over copulation duration in concert with sexual selection and natural selection (see Brennan and Prum 2014).

Moreover, in Argiope lobata, sexual cannibalism not only prolongs the first copulation, but also significantly enhances plugging success (Nessler et al. 2009). This correlation can be viewed as evidence for male investment into a given female or for female choice. The female choice explanation implies that to disfavor a certain male, females would need to refrain from cannibalism. However, observations suggest that females indiscriminately attack every male during copulation (Nessler et al. 2009). Indeed, female influences may become important after copulation. A. lobata females seem to control sperm storage, and how much they store of a given male is independent of copulation duration (Welke and Schneider 2009). Females of the congener A. bruennichi also exert control over relative paternity independently of the duration of copulation by favoring males that courted more (Schneider and Lesmono 2009). Although these studies seem straightforward examples of cryptic female choice (Eberhard 2004b), it remains to be seen whether these findings apply to many other species (see Albo et al. 2013). In particular, it is unclear how fitness relevant the option for cryptic female choice will be in nature. 
J.M. Schneider

From the male perspective, paternity success may be enhanced not only by engaging in longer copulations, but also by repeated copulations with the same female. Male redback spiders survive the somersault during their first copulation, and their return to inseminate and plug the other side will result in fertilization of the majority of this female's eggs. Females are more likely to cannibalize a male during the first copulation if the male had shown a weak courtship performance. Hence, through sexual cannibalism during the first copulation, polyandrous females restrict the paternity success of a male (Stoltz et al. 2008). Many studies have shown that multiple mating, at least in modest rates, is beneficial for females as, for instance, negative effects of incompatibility are reduced (Zeh and Zeh 2001, 2003; Cornell and Tregenza 2007) and the genetic diversity of their offspring increased (reviewed in Jennions and Petrie 2000). In species in which males have evolved means to protect their paternity, females with two spermathecae that are inseminated via different ducts should have an interest in avoiding repeated copulations with the same male. Few studies have tested this prediction in cannibalistic species, but the available studies found no evidence for females selectively rejecting males with which they previously mated (Fromhage and Schneider 2005b; Tuni and Bilde 2010). There are two explanations for the absence of discrimination. One is that there are no costs or perhaps even benefits of remating with the same male. The other is based on the possible constraint that females do not possess the sensory capacity for discriminating individual males even though they would benefit from avoiding repeated copulations with the same male. This may occur if selection on discrimination would be relatively weak, for example, because occurrences are kept in low frequencies caused by an alternative mechanism such as sexual cannibalism after the first copulation. Thereby, females can prevent a male from returning and monopolizing her. Another prediction from the hypothesis would be that the costs of remating for females have to be larger than the gains for males because otherwise selection on males to remate would be stronger than selection on females to prevent remating.
In monogynous mating systems, males are under particularly strong selection to protect their paternity with a single female, and this may at least in some cases override female interests. If male and female interests are opposed, antagonistic coevolution over monopolization may reveal itself in the mating patterns, for example, in the frequency of sexual cannibalism after the first copulation and in the efficiency of paternity protection. In A. bruennichi, $83 \%$ of the males that copulate with a virgin female leave a highly effective plug in one of her two genital openings (Nessler et al. 2007). Indeed, females stereotypically attack every male within one second of genital contact, and up to $80 \%$ of the males do not survive the first copulation (Fig. 2). A male that survives the first copulation can return and plug the second opening, and he thereby monopolizes paternity with this female with a very high certainty. However, the female does not compromise fertilization success by preventing a second copulation, because a single sperm load contains sufficient sperm to fertilize all of her eggs (Schneider et al. 2005). Males that survive the first copulation by terminating copulation within $10 \mathrm{~s}$ still secure a sig-

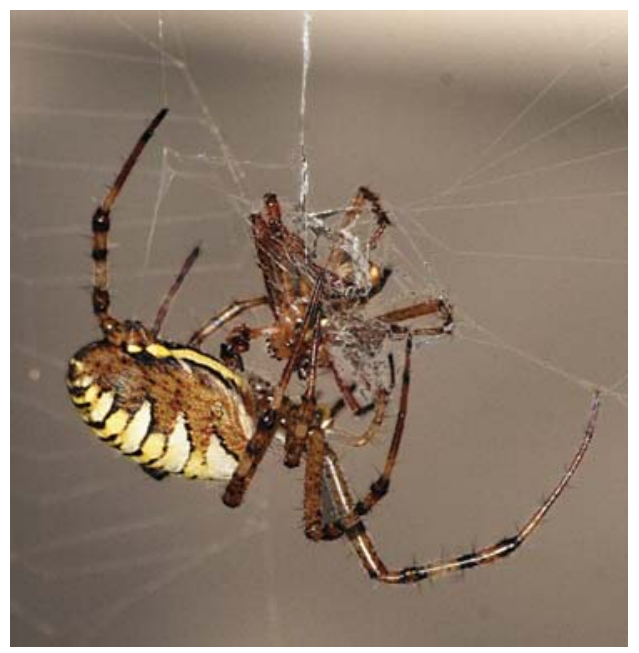

Figure 2. Sexual cannibalism in A. bruennichi. The larger female has wrapped the smaller male in silk after a successful copulation had occurred. (Reprinted, with permission, from Stefan Nessler who holds the copyright.) 
nificant proportion of paternity, even if the female remates, by transferring thousands of spermatozoa and setting a plug in this short time. If these patterns evolved under sexual conflict, we would expect a coevolution of female attack timing and frequency, on the one hand, and the speed of sperm transfer, on the other hand. Because of this dramatic copulation scenario, we predicted that females of $A$. bruennichi would benefit from multiple mating. The potential for cryptic female choice that has been shown in the species (Schneider and Lesmono 2009) may be such a benefit. However, so far, other pronounced indirect or direct fitness benefits of multiple mating without the effect of cannibalism have not been found in this species (Welke and Schneider 2012). However, in double mating experiments, female choice has not been included. To date, only a handful of studies exist that identified benefits of polyandry in spiders (e.g., Watson 1998; Uhl et al. 2005; Maklakov and Lubin 2006; Tuni et al. 2013).

In summary, females may not be very selective, although they may apply a general "screening" as mentioned above by testing male resistance to an attack before mating and during mating. Polyandry may be used as a bethedging strategy. Mechanisms of cryptic female choice will further enhance the options of such a strategy, as it permits biasing paternity toward a preferred sire. One testable prediction of this hypothesis would be that females of species that do not discriminate males before copulation are more likely to benefit from multiple mating than species that reject males by preventing copulation. In other words, females may rely more strongly on polyandry if their options of precopulatory choice are limited. However, evidence is mixed and more data are required to decide whether or not the hypothesis generally holds.

\section{SEXUAL CANNIBALISM AS PATERNAL INVESTMENT}

In some species, males are very successful in monopolizing females, perhaps because females do not resist monogamy or do not actively facilitate polyandry. In such a situation, sexual conflict is modest and male sacrifice could be interpreted as a paternal investment strategy (modeled by Buskirk et al. 1984). However, males are often much smaller than the average prey of the females, and direct fecundity effects of sexual cannibalism were not found in species in which both males and females have low mating rates (Fromhage et al. 2003). Please note that not all species in question have been investigated and that feeding on a male may have nutritional benefits unrelated to his body mass, for example, by providing limiting essential nutrients. Surprisingly, despite this being a long-standing hypothesis, its relevance is still unclear (Wilder et al 2009). A recent experiment provided some suggestive evidence for this idea. Female A. bruennichi, which were experimentally fed a male, produced offspring that survived winter conditions better than offspring of females that were experimentally prevented from cannibalism (Welke and Schneider 2012). Consistent with the paternal investment hypothesis, natural mating rates of both sexes in this species are very low and many females mate with only one male (Zimmer et al. 2012). Furthermore, males are very effective in placing mating plugs, leading to a relatively high paternity security in males. Under such circumstances, it may benefit the male to invest in improving his mate's condition, if this enhances offspring fitness, as his sacrifice will unlikely benefit a future rival. Overall, however, the paternal investment hypothesis of sexual cannibalism has received little support, and based on our current knowledge, it is unlikely to contribute generally to a better understanding of the phenomenon. Enhancement of female condition or offspring quality through the male's investment of soma may become relevant once a largely monogamous mating system has evolved and male and female interests coincide (Holland and Rice 1999).

\section{CONCLUDING REMARKS}

Sexual conflict and antagonistic coevolution is important in species with sexual cannibalism and the interests of the sexes may diverge over control of copulation duration and remating. 
J.M. Schneider

Female predators such as spiders and praying mantis have the potential to kill an unwelcome suitor at low costs, and they may gain a more or less profitable meal to compensate for the energetic costs of the lunge. Thus, we can expect that selection on males is so strong that any trait which reduces the risk of being killed before copulation will rapidly spread. As a result, a proportion of males will still be eaten and killed before insemination, but those are very likely individuals that are in a poor condition or that may have misinterpreted the intentions of the female they approached as being ready to mate, whereas in fact, these were actually on the hunt. However, perhaps as a result of a power asymmetry with dominant females and relatively powerless males, which reduces the costs and risks for the female, sexual cannibalism has become a means in the sexual conflict for control of mating. Despite an easy identification of the victim of the aggression, it is not legitimate to deduce which sex is in control from this observation alone. Indeed, even male victims can benefit from sexual cannibalism.

In this brief essay, I emphasized cases in which sexual cannibalism is more than a side effect of foraging and failed signaling but instead can be considered a regular component of the mating sequence. In monogynous mating systems, males are adapted to invest maximally in fertilizing the eggs of a single female and this investment often includes damage to their genitalia and a loss of their life. Indeed, by accepting or even inviting sexual cannibalism, males can at least sometimes enhance their paternity success by prolonging copulation duration, increasing sperm transfer, facilitating the placement of mating plugs, and perhaps the transfer of manipulative seminal substances. As soon as these mating strategies oppose female interests, sexually antagonistic coevolution will favor female counteradaptations. If females benefit from polyandry, selection will favor adaptations that prevent males from monopolizing fertilization of all her eggs. However, if this female benefit is to retain options for cryptic choice, it is not polyandry per se that is beneficial (Wedell 2013). In contrast, whether or not a particular female benefits from polyandry will depend on the quality and compatibility of her first male. Indeed, there is evidence from redback spiders that females selectively kill disfavored males after the first copulation, although they accept monopolization by preferred males.

In many species, males may apply costly plugs, but they may not always prevent sperm competition. Low plug effectiveness would relax selection on females to kill males during the first copulation. A sexual conflict scenario would be supported if there was a correlation between plug effectiveness and the frequency of premature sexual cannibalism.

Behavioral observations as well as the morphology of the genital apparatus are suggestive of a sexual conflict over control of mating in several spider species. If sexual cannibalism or more accurately the attack behavior of females during copulation is a result of sexual conflict, we can make a number of predictions that still wait to be tested:

1. Sexual cannibalism during the first copulation is particularly common in species with monogynous/bigynous mating systems (active self-sacrifice may have to be excluded here as it cannot be attributed to the female aggressively pushing her interest).

2. Female attacks during mating more often result in male death in species in which male monopolization potential is high.

3. Genital detachment and/or remote copulation occurs when females benefit from control of copulation frequency and duration.

Tests of these comparative predictions would be most revealing if they could be correlated with a phylogenetic hypothesis. The recent advents of molecular methods for reconstructions of phylogenetic trees have been applied to several spider families relevant in this context, and the increasing number of researchers striving to increase our knowledge of spider mating systems allows an optimistic prognosis that the above predictions will be tested in the very near future (Eberhard 2004b). Ideally, the comparative method will be combined with replicated experimental studies (Rönn et al. 2007). 


\section{ACKNOWLEDGMENTS}

I am grateful to Sergey Gavrilets and Bill Rice for inviting me to contribute to this collection. I thank Mark Elgar, Lutz Fromhage, Jannis Liedtke, Rainer Neumann, Jasmin Ruch, Wiebke Schuett, Gabriele Uhl, and Steffi Zimmer for critically reading the text and two referees for constructive comments. Special thanks to Monika Hänel for drawing the figure and to Claudia Drees for editing.

\section{REFERENCES}

${ }^{*}$ Reference is also in this collection.

Aisenberg A, Costa FG, Gonzalez M. 2011. Male sexual cannibalism in a sand-dwelling wolf spider with sex role reversal. Biol J Linn Soc Lond 103: 68-75.

Albo MJ, Toft S, Bilde T. 2012. Female spiders ignore condition-dependent information from nuptial gift wrapping when choosing mates. Anim Behav 84: 907-912.

Albo MJ, Bilde T, Uhl G. 2013. Sperm storage mediated by cryptic female choice for nuptial gifts. Proc Biol Sci 280: 20131735.

Alonzo SH, Pizzari T. 2013. Selection on female remating interval is influenced by male sperm competition strategies and ejaculate characteristics. Phil Trans R Soc B 368: 20120044.

Andersen T, Bollerup K, Toft S, Bilde T. 2008. Why do males of the spider Pisaura mirabilis wrap their nuptial gifts in silk: Female preference or male control? Ethology 114: $775-781$.

Andrade MCB. 1996. Sexual selection for male sacrifice in the Australian redback spider. Science 271: 70-72.

Andrade MCB, Gu L, Stoltz JA. 2005. Novel male trait prolongs survival in suicidal mating. Biol Lett 1: 276-279.

Arnqvist G, Henriksson S. 1997. Sexual cannibalism in the fishing spider and a model for the evolution of sexual cannibalism based on genetic constraints. Evol Ecol 11: 255-273.

Barry KL, Kokko H. 2010. Male mate choice: Why sequential choice can make its evolution difficult. Anim Behav 80: $163-169$.

Barry KL, Holwell GI, Herberstein ME. 2010. Multimodal mate assessment by male praying mantids in a sexually cannibalistic mating system. Anim Behav 79: 1165-1172.

Becker E, Riechert S, Singer F. 2005. Male induction of female quiescence/catalepsis during courtship in the spider, Agelenopsis aperta. Behaviour 142: 57-70.

Berning AW, Gadd RDH, Sweeney K, MacDonald L, Eng RYY, Hess ZL, Pruitt JN. 2012. Sexual cannibalism is associated with female behavioural type, hunger state and increased hatching success. Anim Behav 84: 715721.

Bleakley BH, Welter SM, McCauley-Cole K, Shuster SM, Moore AJ. 2013. Cannibalism as an interacting phenotype: Precannibalistic aggression is influenced by social partners in the endangered Socorro Isopod (Thermosphaeroma thermophilum). J Evol Biol 26: 832-842.

* Brennan PLR, Prum RO. 2014. Mechanisms and evidence of genital coevolution. Cold Spring Harb Perspect Biol doi: 10.1101/cshperspect.a017749.

Buskirk RE, Frohlich C, Ross KG. 1984. The natural selection of sexual cannibalism. Am Nat 123: 612-625.

Chapman T, Liddle LF, Kalb JM, Wolfner MF, Partridge L. 1995. Cost of mating in Drosophila melanogaster females is mediated by male accessory-gland products. Nature 373: $241-244$.

Cornell SJ, Tregenza T. 2007. A new theory for the evolution of polyandry as a means of inbreeding avoidance. $\operatorname{Proc} R$ Soc B 274: 2873-2879.

Eberhard WG. 1996. Female control: Sexual selection by cryptic female choice. Princeton University Press, Princeton, NJ.

Eberhard WG. 2004a. Male-female conflict and genitalia: Failure to confirm predictions in insects and spiders. Biol Rev 79: 121-186.

Eberhard WG. 2004b. Why study spider sex: Special traits of spiders facilitate studies of sperm competition and cryptic female choice. J Arachnol 32: 545-556.

* Edward DA, Stockley P, Hosken DJ. 2014. Sexual conflict and sperm competition. Cold Spring Harb Perspect Biol doi: $10.1101 /$ cshperspect.a017707.

Elgar MA. 1991. Sexual cannibalism, size dimorphism. and courtship behavior in orb-weaving spiders (Araneidae). Evolution 45: 444-448.

Elgar MA. 1992. Sexual cannibalism in spiders and other invertebrates. In Cannibalism (ed. Elgar MA, Crespi BJ), pp. 128-155. Oxford, New York.

Elgar MA. 1995. The duration of copulation in spiders: Comparative patterns. Records of the Western Australian Museum, Perth, Australia, pp. 1-11.

Elgar MA, Nash DR. 1988. Sexual cannibalism in the garden spider Araneus diadematus. Anim Behav 36: 1511-1517.

Elgar MA, Schneider JM. 2004. Evolutionary significance of sexual cannibalism. In Advances in the study of behavior (ed. Slater JB, et al.), Vol. 34, pp. 135-163. Academic, San Diego.

Elgar MA, Schneider JM, Herberstein ME. 2000. Female control of paternity in the sexually cannibalistic spider Argiope keyserlingi. Proc Biol Sci 267: 2439-2443.

Foelix RF. 2011. Biology of spiders. Oxford University Press, Oxford.

Foellmer MW, Fairbairn DJ. 2003. Spontaneous male death during copulation in an orb-weaving spider. Proc Biol Sci 270: S183-S185.

Forster LM. 1992. The stereotyped behavior of sexual cannibalism in Latrodectus hasselti Thorell (Araneae, Theridiidae), the Australian redback spider. Aust J Zool 40: $1-11$.

Fromhage L, Schneider J. 2005a. Virgin doves and mated hawks: Contest behaviour in a spider. Anim Behav 70: 1099-1104.

Fromhage L, Schneider JM. 2005b. No discrimination against previous mates in a sexually cannibalistic spider Naturwissenschaften 92: 423-426. 
J.M. Schneider

Fromhage L, Schneider JM. 2005c. Safer sex with feeding females: Sexual conflict in a cannibalistic spider. Behav Ecol 16: 377-382.

Fromhage L, Schneider JM. 2006. Emasculation to plug up females: The significance of pedipalp damage in Nephila fenestrata. Behav Ecol 17: 353-357.

Fromhage L, Schneider JM. 2012. A mate to die for? A model of conditional monogyny in cannibalistic spiders. Ecol Evol 2: 2572-2582.

Fromhage L, Uhl G, Schneider JM. 2003. Fitness consequences of sexual cannibalism in female Argiope bruennichi. Behav Ecol Sociobiol 55: 60-64.

Fromhage L, Elgar MA, Schneider JM. 2005. Faithful without care: The evolution of monogyny. Evolution 59: 1400-1405.

Fromhage L, McNamara JM, Houston AI. 2008. A model for the evolutionary maintenance of monogyny in spiders. $J$ Theor Biol 250: 524-531.

Goto T, Yoshida M. 1985. The mating sequence of the benthic arrowworm Spadella schizoptera. Biol Bull 169: $328-333$.

Gould SJ. 1984. Only his wings remained. Nat Hist 93: 1018.

Halliday TR. 1983. The study of mate choice. In Mate choice (ed. Bateson P), pp. 3-32. Cambridge University Press, Cambridge.

Herberstein ME, Schneider JM, Harmer AMT, Gaskett AC, Robinson K, Shaddick K, Soetkamp D, Wilson PD, Pekar S, Elgar MA. 2011. Sperm storage and copulation duration in a sexually cannibalistic spider. J Ethol 29: 9-15.

Holland B, Rice WR. 1999. Experimental removal of sexual selection reverses intersexual antagonistic coevolution and removes a reproductive load. Proc Natl Acad Sci 96: 5083-5088.

Jennions MD, Petrie M. 2000. Why do females mate multiply? A review of the genetic benefits. Biol Rev Camb Phil Soc 75: 21-64.

Johnson JC. 2001. Sexual cannibalism in fishing spiders (Dolomedes triton): An evaluation of two explanations for female aggression towards potential mates. Anim Behav 61: 905-914.

Johnson JC. 2013. Debates: Challenging a recent challenge to the aggressive spillover hypothesis. Ethology 119: $811-$ 813.

Johnson JC, Trubl P, Blackmore V, Miles L. 2011. Male black widows court well-fed females more than starved females: Silken cues indicate sexual cannibalism risk. Anim Behav 82: $383-390$.

Kelly CD, Jennions MD. 2011. Sexual selection and sperm quantity: Meta-analyses of strategic ejaculation. Biol Rev 86: $863-884$.

Knoflach B, van Harten A. 2001. Tidarren argo sp. Nov. (Araneae: Theridiidae) and its exceptional copulatory behaviour: Emasculation, male palpal organ as a mating plug and sexual cannibalism. J Zool 254: 449-459.

Kokko H, Mappes J. 2005. Sexual selection when fertilization is not guaranteed. Evolution 59: 1876-1885.

Kokko H, Mappes J. 2013. Multiple mating by females is a natural outcome of a null model of mate encounters. Entomol Exp Appl 146: 26-37.
Kralj-Fišer S, Schneider JM. 2012. Individual behavioural consistency and plasticity in an urban spider. Anim Behav 84: 197-204.

Kralj-Fišer S, Gregoric M, Zhang SC, Li DQ, Kuntner M. 2011. Eunuchs are better fighters. Anim Behav 81: $933-$ 939.

Kralj-Fišer S, Schneider JM, Justinek Z, Kalin S, Gregoric M, Pekar S, Kuntner M. 2012. Mate quality, not aggressive spillover, explains sexual cannibalism in a size-dimorphic spider. Behav Ecol Sociobiol 66: 145-151.

Kralj-Fišer S, Mostajo GAS, Preik O, Pekar S, Schneider JM. 2013a. Assortative mating by aggressiveness type in orb weaving spiders. Behav Ecol 24: 824-831.

Kralj-Fišer S, Schneider JM, Kuntner M. 2013b. Challenging the aggressive spillover hypothesis: Is pre-copulatory sexual cannibalism a part of a behavioural syndrome? Ethology 119: 615-623.

Kuntner M, Coddington JA, Schneider JM. 2009a. Intersexual arms race? Genital coevolution in Nephilid spiders (Araneae, Nephilidae). Evolution 63: 1451-1463.

Kuntner M, Kralj-Fišer S, Schneider JM, Li D. 2009b. Mate plugging via genital mutilation in nephilid spiders: An evolutionary hypothesis. J Zool 277: 257-266.

Kvarnemo C, Simmons LW. 2013. Polyandry as a mediator of sexual selection before and after mating. Phil Trans $R$ Soc Lond B Biol Sci 368: 20120042.

Lee QQ, Oh J, Kralj-Fiser S, Kuntner M, Li DQ. 2012. Emasculation: Gloves-off strategy enhances eunuch spider endurance. Biol Lett 8: 733-735.

Lelito JP, Brown WD. 2006. Natural history miscellanyComplicity or conflict over sexual cannibalism? Male risk taking in the praying mantis Tenodera aridifolia sinensis. Am Nat 168: 263-269.

Li DQ, Oh J, Kralj-Fiser S, Kuntner M. 2012. Remote copulation: Male adaptation to female cannibalism. Biol Lett 8: $512-515$.

Maklakov AA, Lubin Y. 2006. Indirect genetic benefits of polyandry in a spider with direct costs of mating. Behav Ecol Sociobiol 61: 31-38.

Michiels NK, Raven-Yoo-Heufes A, Brockmann KK. 2003. Sperm trading and sex roles in the hermaphroditic opisthobranch sea slug Navanax inermis: Eager females or opportunistic males? Biol J Linn Soc Lond 78: 105-116.

Miller JA. 2007. Repeated evolution of male sacrifice behavior in spiders correlated with genital mutilation. Evolution 61: 1301-1315.

Morrow EH, Arnqvist G, Pitnick S. 2003. Adaptation versus pleiotropy: Why do males harm their mates? Behav Ecol 14: $802-806$.

Moya-Larano J, Orta-Ocana JM, Barrientos JA, Bach C, Wise DH. 2003. Intriguing compensation by adult female spiders for food limitation experienced as juveniles. Oikos 101: 539-548.

Moya-Larano J, Pascual J, Wise DH. 2004. Approach strategy by which male Mediterranean tarantulas adjust to the cannibalistic behaviour of females. Ethology 110: 717724.

Nessler SH, Uhl G, Schneider JM. 2007. Genital damage in the orb-web spider Argiope bruennichi (Araneae: Araneidae) increases paternity success. Behav Ecol 18: 174-181. 
Nessler S, Uhl G, Schneider J. 2009. Sexual cannibalism facilitates genital damage in Argiope lobata (Araneae: Araneidae). Behav Ecol Sociobiol 63: 355-362.

Neumann R, Schneider JM. 2011. Frequent failure of male monopolization strategies as a cost of female choice in the black widow spider latrodectus tredecimguttatus. Ethology 117: $1057-1066$

Newman JA, Elgar MA. 1991. Sexual cannibalism in orbweaving spiders-An economic model. Am Nat 138: 1372-1395.

* Perry JC, Rowe L. 2014. The evolution of sexually antagonistic phenotypes. Cold Spring Harb Perspect Biol doi: 10.1101/cshperspect.a017558.

Polis GA. 1981. The evolution and dynamics of intraspecific predation. Annu Rev Ecol Syst 12: 225-251.

Prenter J, MacNeil C, Elwood RW. 2006. Sexual cannibalism and mate choice. Anim Behav 71: 481-490.

Prokop P, Maxwell MR. 2009. Female feeding regime and polyandry in the nuptially feeding nursery web spider, Pisaura mirabilis. Naturwissenschaften 96: 259-265.

Pruitt JN, Keiser CN. 2013. Debates: The aggressive spillover hypothesis: Existing ailments and putative remedies. Ethology 119: 807-810.

Pruitt JN, Riechert SE. 2012. The ecological consequences of temperament in spiders. Curr Zool 58: 589-596.

Rabaneda-Bueno R, Rodriguez-Girones MA, Aguado-DeLa-Paz S, Fernandez-Montraveta C, De Mas E, Wise DH, Moya-Larano J. 2008. Sexual cannibalism: High incidence in a natural population with benefits to females. PLOS ONE 3: 1.

Ram KR, Wolfner MF. 2007. Seminal influences: Drosophila Acps and the molecular interplay between males and females during reproduction. Integr Comp Biol 47: 427-445.

Real L. 1990. Search theory and mate choice: 1 . Models of single-sex discrimination. Am Nat 136: 376-405.

Robinson M. 1982. Courtship and mating behavior in spiders. Annu Rev Entomol 27: 1-20.

Robinson MH, Robinson B. 1973. Ecology and behaviour of the giant wood spider Nephila maculata (Fabricius) in New Guinea. Smithson Contrib Zool 149: 1-76.

Robinson MH, Robinson B. 1980. Comparative studies of the courtship and mating behaviour of tropical araneid spiders. In Pacific insects monograph, 218 pp. Bishop Museum, Honolulu, HI.

Rönn J, Katvala M, Arnqvist G. 2007. Coevolution between harmful male genitalia and female resistance in seed beetles. Proc Natl Acad Sci 104: 10921-10925.

Schneider JM, Andrade MCB. 2011. Mating behaviour and sexual selection, pp. 215-274. Cambridge University Press, Cambridge.

Schneider JM, Fromhage L. 2010. Monogynous mating strategies in spiders. In Behaviour: Evolution and mechanisms (ed. Kappeler PI). Springer, Heidelberg, Germany.

Schneider JM, Lesmono K. 2009. Courtship raises male fertilization success through post-mating sexual selection in a spider. Proc Biol Sci 276: 3105-3111.

Schneider JM, Fromhage L, Uhl G. 2005. Extremely short copulations do not affect hatching success in Argiope bruennichi (Araneae, Araneidae). J Arachnol 33: $663-$ 669.

Schneider JM, Thomas ML, Elgar MA. 2001. Ectomised conductors in the golden orb-web spider, Nephila plumipes (Araneoidea): A male adaptation to sexual conflict? Behav Ecol Sociobiol 49: 410-415.

Schneider JM, Gilberg S, Fromhage L, Uhl G. 2006. Sexual conflict over copulation duration in a cannibalistic spider. Anim Behav 71: 781-788.

Schutz D, Taborsky M. 2005. Mate choice and sexual conflict in the size dimorphic water spider Argyroneta aquatica (Araneae, Argyronetidae). J Arachnol 33: 767-775.

Schutz D, Taborsky M. 2011. Sexual selection in the water spider: Female choice and male-male competition. Ethology 117: 1101-1110.

Schwartz SK, Wagner WE, Hebets EA. 2013. Spontaneous male death and monogyny in the dark fishing spider. Biol Lett 9: 20130113.

Segoli M, Arieli R, Sierwald P, Harari AR, Lubin Y. 2008. Sexual cannibalism in the brown widow spider (Latrodectus geometricus). Ethology 114: 279-286.

Sentenska L, Pekar S. 2013. Mate with the young, kill the old: Reversed sexual cannibalism and male mate choice in the spider Micaria sociabilis (Araneae: Gnaphosidae). Behav Ecol Sociobiol 67: 1131-1139.

Singer F, Riechert SE, Xu HF, Morris AW, Becker E, Hale JA, Noureddine MA. 2000. Analysis of courtship success in the funnel-web spider Agelenopsis aperta. Behaviour 137: 93-117.

* Sirot LK, Wong A, Chapman T, Wolfner MF. 2014. Sexual conflict and seminal fluid proteins: A dynamic landscapte of sexual interactions. Cold Spring Harb Perspect Biol doi: 10.1101/cshperspect.a017533.

Snow LSE, Andrade MCB. 2004. Pattern of sperm transfer in redback spiders: Implications for sperm competition and male sacrifice. Behav Ecol 15: 785-792.

Snow LSE, Abdel-Mesih A, Andrade MCB. 2006. Broken copulatory organs are low-cost adaptations to sperm competition in redback spiders. Ethology 112: 379-389.

Stoltz JA, Elias DO, Andrade MCB. 2008. Females reward courtship by competing males in a cannibalistic spider. Behav Ecol Sociobiol 62: 689-697.

Tuni C, Bilde T. 2010. No preference for novel mating partners in the polyandrous nuptial-feeding spider Pisaura mirabilis (Araneae: Pisauridae). Anim Behav 80: 435442.

Tuni C, Albo MJ, Bilde T. 2013. Polyandrous females acquire indirect benefits in a nuptial feeding species. J Evol Biol 26: $1307-1316$.

Uhl G, Elias DO. 2011. Communication. In Spider behaviour: Flexibility and versatility (ed. Herberstein ME), pp. 127-189. Cambridge University Press, Cambridge.

Uhl G, Schmitt S, Schafer M. 2005. Fitness benefits of multiple mating versus female mate choice in the cellar spider (Pholcus phalangioides). Behav Ecol Sociobiol 59: 69-76.

Uhl G, Nessler SH, Schneider J. 2007. Copulatory mechanism in a sexually cannibalistic spider with genital mutilation (Araneae: Araneidae: Argiope bruennichi). Zoology 110: 398-408.

Uhl G, Nessler S, Schneider J. 2009. Securing paternity in spiders? A review on occurrence and effects of mat- 
J.M. Schneider

ing plugs and male genital mutilation. Genetica 138: 75104.

Uhl G, Nessler S, Schneider J. 2010. Securing paternity in spiders? A review on occurrence and effects of mating plugs and male genital mutilation. Genetica 138: 75-104.

Watanabe H, Yano E. 2012. Behavioral response of male mantid Tenodera aridifolia (Mantodea: Mantidae) to windy conditions as a female approach strategy. Entomol Sci 15: 384-391.

Watson PJ. 1998. Multi-male mating and female choice increase offspring growth in the spider Neriene litigiosa (Linyphiidae). Anim Behav 55: 387-403.

Wedell N. 2013. The dynamic relationship between polyandry and selfish genetic elements. Phil Trans $R$ Soc Lond B Biol Sci 368: 20120049.

Welke KW, Schneider J. 2009. Inbreeding avoidance through cryptic female choice in the cannibalistic orb-web spider Argiope lobata. Behav Ecol 20: 1056-1062.

Welke KW, Schneider JM. 2010. Males of the orb-web spider Argiope bruennichi sacrifice themselves to unrelated females. Biol Lett 6: 585-588.

Welke KW, Schneider JM. 2012. Sexual cannibalism benefits offspring survival. Anim Behav 83: 201-207.

Welke KW, Zimmer SM, Schneider JM. 2012. Conditional monogyny: Female quality predicts male faithfulness. Front Zool 9: 7.
Wilder SM, Rypstra AL. 2007. Male control of copulation duration in a wolf spider (Araneae, Lycosidae). Behaviour 144: $471-484$.

Wilder SM, Rypstra AL. 2008. Sexual size dimorphism predicts the frequency of sexual cannibalism within and among species of spiders. Am Nat 172: 431-440.

Wilder SM, Rypstra AL, Elgar MA. 2009. The importance of ecological and phylogenetic conditions for the occurrence and frequency of sexual cannibalism. Annu Rev Ecol Evol Syst 40: 21-39.

Wilgers DJ, Hebets EA. 2012. Age-related female mating decisions are condition dependent in wolf spiders. Behav Ecol Sociobiol 66: 29-38.

Zeh JA, Zeh DW. 2001. Reproductive mode and the genetic benefits of polyandry. Anim Behav 61: 1051-1063.

Zeh JA, Zeh DW. 2003. Toward a new sexual selection paradigm: Polyandry, conflict and incompatibility. Ethology 109: 929-950.

Zhang SC, Kuntner M, Li DQ. 2011. Mate binding: Male adaptation to sexual conflict in the golden orb-web spider (Nephilidae: Nephila pilipes). Anim Behav 82: 12991304.

Zimmer SM, Welke KW, Schneider JM. 2012. Determinants of natural mating success in the cannibalistic orb-web spider Argiope bruennichi. PLoS ONE 7: e31389. 


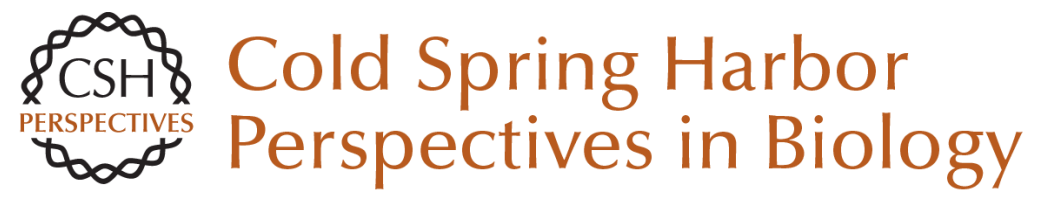

\section{Sexual Cannibalism as a Manifestation of Sexual Conflict}

Jutta M. Schneider

Cold Spring Harb Perspect Biol 2014; doi: 10.1101/cshperspect.a017731 originally published online September 11, 2014

\section{Subject Collection The Genetics and Biology of Sexual Conflict}

Mechanisms and Evidence of Genital Coevolution: The Roles of Natural Selection, Mate Choice, and Sexual Conflict

Patricia L.R. Brennan and Richard O. Prum

The Evolution of Sexually Antagonistic Phenotypes

Jennifer C. Perry and Locke Rowe

Reproductive Parasitism: Maternally Inherited

Symbionts in a Biparental World

Gregory D.D. Hurst and Crystal L. Frost

Sex-Biased Gene Expression and Sexual Conflict throughout Development

Fiona C. Ingleby, Ilona Flis and Edward H. Morrow

Human Homosexuality: A Paradigmatic Arena for

Sexually Antagonistic Selection?

Andrea Camperio Ciani, Umberto Battaglia and Giovanni Zanzotto

Sexual Conflict Arising from Extrapair Matings in Birds

Alexis S. Chaine, Robert Montgomerie and Bruce E. Lyon

Sexual Conflict and Seminal Fluid Proteins: A

Dynamic Landscape of Sexual Interactions

Laura K. Sirot, Alex Wong, Tracey Chapman, et al.

Conflict on the Sex Chromosomes: Cause, Effect, and Complexity

Judith E. Mank, David J. Hosken and Nina Wedell
Infanticide as Sexual Conflict: Coevolution of

Male Strategies and Female Counterstrategies Ryne A. Palombit

Copulatory Wounding and Traumatic Insemination

Klaus Reinhardt, Nils Anthes and Rolanda Lange

Sexual Conflict in Hermaphrodites

Lukas Schärer, Tim Janicke and Steven A. Ramm

Sexual Conflict and Sperm Competition

Dominic A. Edward, Paula Stockley and David J. Hosken

Sexually Antagonistic Zygotic Drive: A New Form of Genetic Conflict between the Sex

Chromosomes

Urban Friberg and William R. Rice

Sex Chromosome Drive

Quentin Helleu, Pierre R. Gérard and Catherine Montchamp-Moreau

Is Sexual Conflict an "Engine of Speciation"? Sergey Gavrilets

Sexual Cannibalism as a Manifestation of Sexual Conflict

Jutta M. Schneider

For additional articles in this collection, see http://cshperspectives.cshlp.org/cgi/collection/

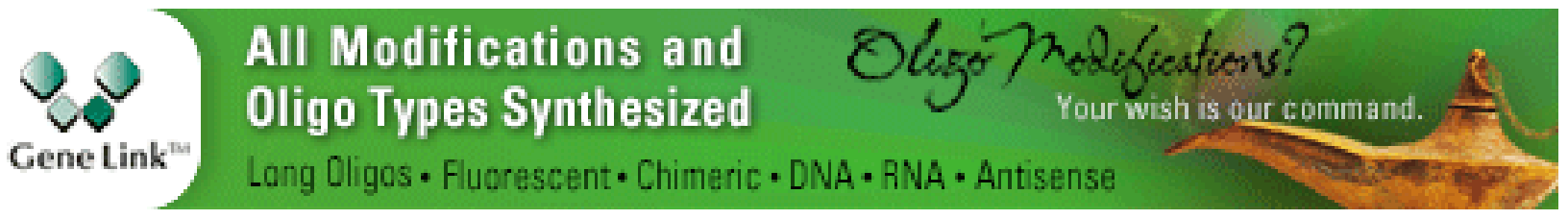

Copyright @ 2014 Cold Spring Harbor Laboratory Press; all rights reserved 
For additional articles in this collection, see http://cshperspectives.cshlp.org/cgi/collection/

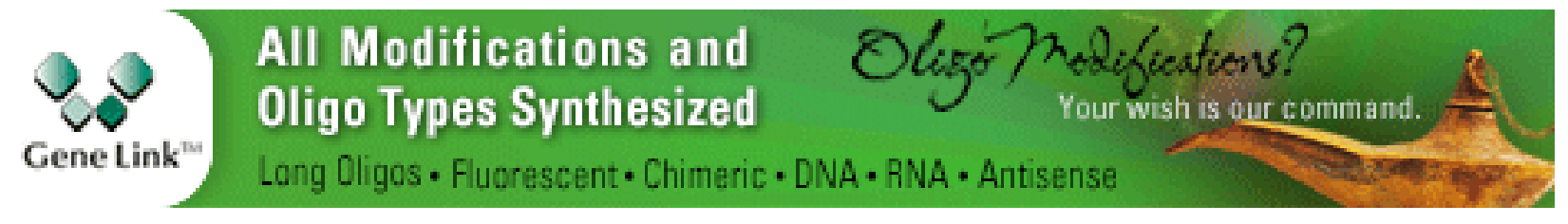

Copyright @ 2014 Cold Spring Harbor Laboratory Press; all rights reserved 